proportional numbers under all circumstances. A change in the shape of the molecules, or an augmentation of their diameters, will affect the first number in a much greater proportion than the second. But, as I have shown, the equation of Van der Waals holds good, independently of this assumption.

Amsterdam, November 4.

\section{T. KORTEWEG.}

\section{THE BIRD-GALLERY IN THE BRITISH MUSEUM.}

A LONG-NEEDED and much-wished-for reform, A to which the attention of naturalists should be specially invited, has been commenced in the Birdgallery of the British Museum. Under the old régime at Bloomsbury, the rule was, as it is even now in most of the Continental Museums, that every specimen should be stuffed, and exhibited in the public gallery. The natural, if not the necessary, consequence of such a rule is that, as time progresses, the shelves become crowded with badly mounted specimens, which are very unpleasing to the general observer, and most inconvenient to the scientific worker.

In the British Museum, however, the idea of mounting every specimen has been long ago abandoned. The main collection for scientific work is, we need hardly say, that of skins. These are arranged in cabinets, in numbers which it would be impossible to find space for if " mounted." When thus disposed of they are much more easy to find, and more convenient for examination, than "mounted" specimens. Though it may be sometimes necessary to refer to the Bird-gallery, the working ornithologist of this country, as a rule, uses only the skin collection.

This being so, the question arises as to what is the best way of making the Bird-gallery useful, and attractive to the general public. As to this there can be no question, it appears, that the Bird-gallery should be fitted up as an "Index Museum," and should contain a series of the principal types of bird-life arranged in systematic order from the highest to the lowest. Every family should be placed in a separate case, in its proper position between the two groups to which it is most nearly allied. In each family a series of well-mounted specimens should illustrate the principal sub-families and genera, and the male and female and other plumage of the leading species. Nests and eggs should be added to show the mode of nidification, and maps to show the areas of distribution. Diagrams and preparations of particular structures should be placed at the head of each group, to exhibit its special peculiarities; and finally, every specimen and diagram should be clearly labelled and explained. It will readily be understood that a Bird-gallery filled up in this way would be a most instructive object, and much more useful and attractive than the crowded rows of uniformlyset-up specimens that are offered to view in most public Museums. Some such plan as this, we take it, is what the authorities of the British Museum have now in view.

For a commencement, the family of Woodpeckers has been selected, and a case devoted to its illustration has been fitted up. A series of well-mounted specimens shows the leading forms of the group, and diagrams, preparations, and maps exhibit its principal peculiarities and the distribution of the species.

This is at present only the beginning of a very important change of plan. But there can be no question that if the scheme is carried out, and the whole Birdgallery is treated in a similar way, an admirable reform will have been effected.

$$
\text { NO. I I 55, VOL. 45] }
$$

\section{THE OCTOBER ERUPTION NORTH-WEST OF PANTELLERIA.}

SOME time after the news arrived in this country of the volcanic outburst in the neighbourhood of Pantelleria, my friend Mr. Gerard Butler, F.G.S., undertook to visit the island, and to investigate the interesting phenomena that were being exhibited there. Mr. Butles has now returned, having made a large collection of specimens of rocks and minerals, and I trust that before long we shall have fuller information concerning this remarkable district. The following short note embodies the general results of his inquiries concerning the recent eruptions; but telegrams received since his return state that renewed outbursts have led to the formation of an island at the spot, and mariners have been warned to avoid it. JOHN W. JUDD.

Royal College of Science, London, December I4.

In NATURE of December 3 (p. I20), a short sketch is given of a paper by M. Ricco on the above, which those interested in the subject may read in the Comptes rendus for November 25.

It may be worth while for one who visited Pantelleria soon after the eruption to point out that there appears to be no foundation for the idea conveyed by many Eng. lish accounts and by the words "island," "erupted island," in NATURE (loc. cit.), that an island comparable to Graham's Island was formed.

It seems that by a submarine eruption which, after prefatory earthquakes between October I4 and I7, was first observed on the latter day, about 5 kilometres to the north-west of Pantelleria, a narrow band of floating bombs, extending for about a kilometre in a north-east and south-west direction, was produced.

The persistence during the eruption of this linear band may perhaps indicate the line of fracture of the sea bottom.

There appears to have been always deep water at the scene of eruption. Ricco tells us that soundings at the middle and ends of the floating shoal of bombs found no bottom at 320 metres.

The brittle cindery bombs readily broke up, giving vent to the superheated steam they contained; when, or upon their becoming otherwise waterlogged, they sank, so that, on October 26 , soon after the eruptive action ceased, all traces of it had disappeared in deep water.

G. W. ButleR.

\section{NOTES.}

WE regret to have to record the death of Prof. Stas, the eminent Belgian chemist. He died at the age of seventy-eight.

AT last Thursday's meeting of the Royal Society, the President read from the chair a letter from Prof. Dewar, which had been put into his hand as he entered the meeting-room, in which Prof. Dewar stated that he had at 3 p.m. that afternoon "placed a quantity of liquid oxygen in the state of rapid ebullition in air (and therefore at a temperature of $-181^{\circ} \mathrm{C}$.) between the poles of the historic Faraday magnet in a cup. shaped piece of rock salt (which is not moistened by liquid oxygen and therefore keeps it in the spheroidal state)," and to his surprise, Prof. Dewar saw the liquid oxygen, as soon as the magnet was stimulated, "suddenly leap up to the poles and remain there permanently attracterl until it evaporated."

ACCORDING to information sent to Berlin, Emin Pasha and Dr. Stuhlmann, travelling in the region between Lakes Victoria, Tanganyika, and Albert Edward, have discovered what they take to be the ultimate source of the Nile. This is a river called Kifu, which is supposed to have its sources in the Uhha country, lying to the east of the northern part of Lake Tanganyika, 